\title{
Matrix Model and Data Processing in Effectiveness Evaluation and Countermeasure of College Education
}

\author{
Yang Tang ${ }^{1, a}$ \\ ${ }^{1}$ Grammar School, Wuhan University of Technology, Wuhan Hubei, China, 430070. \\ aytang@cumt.edu.cn
}

Keywords: College Students, Educational Effectiveness, Evaluation Model, College Education

\begin{abstract}
Advancing the effectiveness of college education is the core of further strengthens and improves college students' education, and is a serious subject that the college education workers must face and think. Under the background of globalization and on the basis of college students' education care, studying on effectiveness of college students' education is put forward as a proposition, it is not only an educational question, but also a political question. From the analysis of factors that affect college students' educational effectiveness, built the evaluation model of educational effectiveness by matrix model, obtained the main factors that influence effectiveness of college students' education by using the data processing method, and finally proposed an improved countermeasure to the improvement of college educational effectiveness.
\end{abstract}

\section{Introduction}

The evaluation of college educational effectiveness is the most important part of integral evaluation system in colleges. On the further strengthening and improving students' education, the opinion of the CPC Central Committee and State Council is made clear that, the college students' education work as an important indicator for evaluating to institutions of higher learning education quality and managerial level incorporated into the construction and teaching evaluation system of the party in colleges. The correct evaluation of teaching effectiveness is an effective method to strengthen the quality of teaching, is a powerful lever to promote the college teaching. Take college teaching as an example, we build evaluation model of college educational effectiveness, obtain the main factors that influence effectiveness of college students' education by using the data processing method, and put forward some countermeasures for improvement.

\section{Analysis of Factors that Affect Educational Effectiveness of College Students' ideological and political}

Objective Factors that Affect College Students' Education $T(x)$

Objective factors mainly include the international and domestic teaching situation, and the education of college internal, and so on and so forth. In terms of college internal, the key is to integrate carrier elements such as the various educational environment, educational methods and educational mechanism, to maximize the potential of educators and students, to complete education activities, then improve students' ideological and political quality, so as to achieve the purpose of tertiary education. To achieve maximum efficiency of education, we must make these carrier elements at their best state, form the largest resultant force. At present, the carrier elements of education are numerous, mainly can be divided into the following categories:

(1) The carrier of management. The carrier of management combines content of the education and management, to infiltrate the teachers' and students' work, study and life, to improve the moral quality, regularize behavioral pattern, arouse the enthusiasm. An important task of college education is to handle the relations between people to people and human to society, the college educational ultimate purpose is to arouse the enthusiasm of people, at this point management have great agree with college education. 
(2) The carrier of services. Service coverage all aspects of life such as teaching and scientific research, it is a bridge that connects schools and the teachers and students emotion, it is the "generator" of centripetal force, cohesion, motivation between teachers and students, it is an important carrier of college education.

(3) The carrier of lessons. Lesson reassures have a variety of functions such as education, management, service, preaching and knowledge in one, is the most formal carrier of student college education. Class is main channel and position to inculcate the basic skills and theories, strengthen the behavior standards, and remove the theoretical misunderstandings, develop a scientific world outlook, the views and values of life. General class except the function of imparting knowledge, but also full of "writing carry doctrine" on education, such as the throughout and penetration of dialectics, the humanistic spirit and scientific spirit, innovative thinking in professional course, teachers' words and deeds of personality education demonstration and so on. Optimize the carrier of the classroom, the teaching and education, more consciously organically, is our important responsibility.

(4) The carrier of activities. Activity carrier is consciously to carry out various activities, lies in the contents of college education activities, in the process of activity education, make people raise awareness. Carrier activities at colleges and universities can be roughly divided into the campus cultural activities, community cultural activities, community activities, youth volunteer activities, social practice, college students' scientific research activities, the activities to promote cultural and ethical progress, etc. These activities are adapted to the exploration and innovation of new changes in colleges and universities situation. With activity as the carrier, it has its unique different with other educational means: one is to make the content of college education to accept quietly; other is to well realizing the unity of education and self education.

The Basic Psychological Quality of College Students $S(x)$

The factors mainly include the young college students' basic psychological quality, life value, intrinsic psychological need, etc. Young students' basic psychological quality is the basis and platform of college education. Although college students are a relatively good peer group, have a good knowledge and skills, qualities, but if they don't have a good psychological quality still can't meet the objective requirement of The Times. "In terms of quality, psychological quality is the most important quality". College education must adhere to the student oriented, in the first place to improve college students' psychological quality, then can really improve college students' psychological quality, and make students have the comprehensive quality of integrate development to meet the needs of the development of era. In this factor, young college student individual the basic quality such as learning enthusiasm, basic knowledge and reflective ability in a particular time period is basically stable, can be assumed as a constant $K$.

Accidental Factors May Change the College Students' Educational Condition $R(x)$

The factors mainly include the mutations of political and economic situation on international and domestic (such as natural disasters, war), a major measure for higher education system in the near future and the other accidental factors college students themselves encounter and so on. Only college education meets the mental needs of college students, and through various channels of education into college students' subject field, can promote the university students to accept and practice through various means. So, university education should fully consider the characteristics of the college students, according to the requirements to design and carry out education activities, improve the occasion, and make them consciously accept the college education, absorb nutrients in education, and improve their comprehensive quality. 


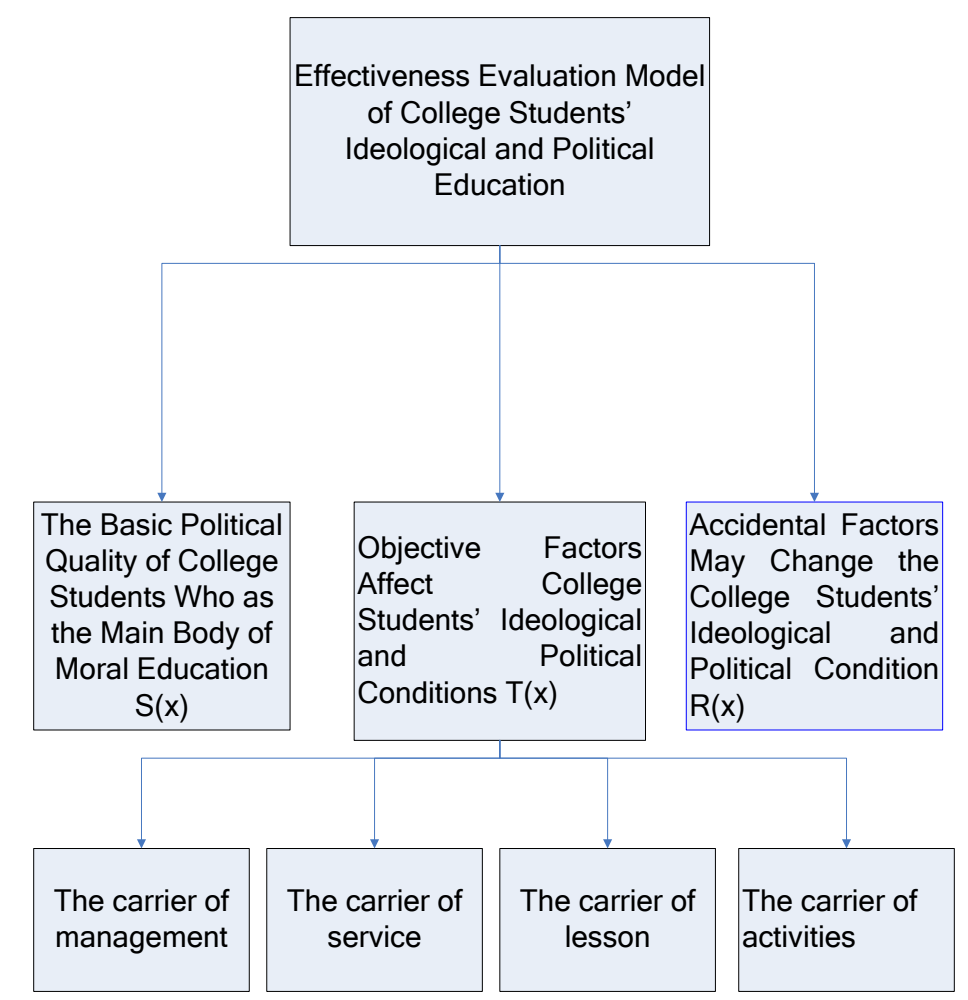

Fig. 1 Build effectiveness evaluation model of college students’ education

\section{The effectiveness evaluation model of college education based on matrix model}

Introduction of matrix model to solve practical problems in student work, especially using quantitative parameters for mathematics as reflect actual effect after students accepting education that is the actual acceptance of variables. In the core operations section of evaluation system, an equation (1) as a quantitative evaluation of mathematical model was introduced.

$$
E(x)=a K F(x) * P(x)
$$

In equation (1), $E(x)$ is a variable, expresses a result due to the combination between objective factors and subjective factors, college student individual conditions $P(x)$ as the individual actual acceptance after input the environment (society, school, family) information, that is a subjective variables of the acceptance for college students to education; $K$ is a constant, as the basic psychological quality and learning enthusiasm of the individual, for individual youth, in a certain period of time it is invariant; $a$ is the correction factor; $F(x)$ means after a series of external environment information input individual, the impact on the individual function, this function is a matrix composed of multiple objective variable modulus, means exterior impact on individuals.

In equation (1), $P(x)$ is the object of study, the scope of its actual value is $-1<P(x)<1$. When $-1<P(x)<1$, individual learning situation is passive and negative, has mental reverse and resistance, actual effect of education is not good, so it is a negative effect; when $0<P(x)<1$, individual learning situation is in positive and certain condition, the effect of guidance and education is good, so it is a positive effect. Further study, by the calibration standard numerical of $E(x)$, could calculate $P(x)$, for example, $P(x)=0.85$ means individuals accepted the actual effect of education is $85 \%$. Thus, we use quantitative mathematical parameters to describe the actual effect of young college students' education.

In equation (1), $F(x)$ is a function.

$$
F(x)=\left[\begin{array}{l}
T_{1}(x), T_{2}(x), T_{3}(x) \ldots \ldots T_{n}(x) \\
S_{1}(x), S_{2}(x), S_{3}(x) \ldots \ldots S_{n}(x) \\
R_{1}(x), R_{2}(x), R_{3}(x) \ldots \ldots R_{n}(x)
\end{array}\right]
$$


In equation (2), $T(x)$ is objective factors of external environment that affects the college students' learning situation; $S(x)$ is factors of college individual had the basic psychological quality; $R(x)$ is impact factors of a series of accidental and uncertain factors on the individual learning situation. The matrix model is used to construct a mathematical function $F(x)$, can calculate its result by specific numerical value of $T(x), R(x)$ and $S(x)$, compared with standard, measure the degree of deviation could determine which factor was the main objective factors affecting youth learning situation. For example, if the standard is $F_{0}(x)=17$, the testing result is $F(x)=14$, then, it can be determine the influence of deviation between the individual dominant factors and standard by the result of an order of magnitude, according to the order of magnitude difference we could find which one is leader in $T(x), R(x)$ and $S(x)$, to further determine individual rational personalized solutions of education. As shown, the value of $n$ is greater, the better the results we get.

\section{The countermeasures of advancing the effectiveness of education in colleges}

In this evaluation system, we use the basic principle and research methods of management psychology, college education activities closely relate to people's psychological phenomenon, so by observed the phenomenon such as the behavior and mood to study the accepted education objects. The evaluation model can also evaluate the learning status of individuals and groups. To individuals, according to actual situation after the assessment, put forward a variety of personalized solutions to improve the performance of education. As long as the individual specific experimental research, truthfully record the individuals response to objective environment stimulate of education, self quality assessment, accidental factors and so on, can use some mathematical methods quantitatively calculate the actual effect of individual education. In the experiment of the whole work, we used five kinds of management method such as the observation method, experimental method, investigation method, test method and case method, to study the individual learning activities, and propose the solution according to the reality problems in individual learning conditions.

When $P(x)$ is negative or its value is very small, mean college student individual can not completely or totally unacceptable to education, that has to actively do a good job to leads, make them recognize the importance of education and individual value, change attitude positively. On the one hand, to make the youth to realize the important of educational social value and individual value, education is an important role in the process of socialization of individual, and it has important guiding significance in the individual social development. On the other hand, make "lead the project" practice activity as the carrier, pioneer of student party members play a good demonstration effect, use the party members' personality, leadership and condensation power to affect people, strengthen the implementation of college education.

When the individual value $\mathrm{K}$ is low, and $P(x)$ relatively with good condition, means students' basic psychological quality is not well, then improved by the ways of courses teaching, social practice and the construction of campus culture and so on.

For $T(x)$ as the leading factors, the corresponding required us to make a good external environment of education, follow the objective law, build great moral education pattern, construct good quality environment of college education and objective carrier.

\section{References}

[1] YANG Hongze, ZHANG Senglin: Theory and Reform Vol. 5 (2013), p.165-167.

[2] YANG Hongze, ZHANG Senglin, Li Zhengzhi: Social Scientist Vol. 3 (2013), p. 151-154.

[3] YANG Hongze, ZHANG Senglin: Theory and Reform Vol.1 (2013), p.148-150.

[4] JIA Xuefeng: Ideological and Political Education Research Vol. 25 (2009), p.92-95. 